\title{
POTENSI TUMBUHAN KELAKAI (Stenochlaena palustris (Burm.F.) Bedd.) ASAL KALIMANTAN TENGAH SEBAGAI AFRODISIAKA
}

\author{
${ }^{1}$ Fahruni, ${ }^{2}$ Rezqi Handayani, ${ }^{2}$ Susi Novaryatiin
}

\author{
'Dosen Pengajar Program Studi Kehutanan, Fakultas Pertanian dan Kehutanan, \\ Universitas Muhammadiyah Palangkaraya \\ 2Dosen Pengajar Program Studi D-III Farmasi, Fakultas IImu Kesehatan, \\ Universitas Muhammadiyah Palangkaraya \\ e-mail : fahruni@yahoo.co.id, rezqi.handayani@gmail.com
}

\begin{abstract}
ABSTRAK
Kebutuhan akan obat tradisional yang berkhasiat sebagai afrodisiaka semakin meningkat setiap tahunnya. Masyarakat Dayak percaya bahwa Akar Kelakai memiliki khasiat sebagai obat afrodisiaka, akan tetapi belum ada penelitian yang dilakukan terkait dengan khasiat Akar Kelakai tersebut. Oleh karena itu perlu dilakukan penelitian untuk membuktikan secara ilmiah tentang penggunaan Akar Kelakai sebagai obat tradisional yang berefek afrodisiaka.

Sehingga dapat dilakukan penelitian lebih lanjut untuk menghasilkan sediaan farmasi yang dapat digunakan oleh masyarakat. Afrodisiaka atau lebih dikenal dengan obat kuat laki-laki adalah obat yang bekerja secara hormonal maupun non hormonal dan sangat erat hubungannya dengan libido seksual. Produk obat tradisional yang berkhasiat sebagai afrodisiaka memiliki efek mirip hormon, biasanya mengandung bahan aktif yang mempunyai sifat antara lain estrogenik, progesteron, androgenik, adaptogenik, dan lektogenik. Bahan yang bersifat androgenik atau adaptogenik bersifat membantu memelihara serta memulihkan stamina.

Tujuan dari penelitian ini adalah untuk mengetahui kandungan senyawa aktif pada Akar Kelakai yang berkhasiat sebagai afrodisiaka dan untuk mengetahui profil Kromatografi Lapis Tipis (KLT) senyawa aktif yang terkandung dalam Akar Kelakai.

Penelitian ini menggunakan metode identifikasi senyawa kimia pati dan aleuron, tanin, katekol, flavonoid, alkaloid, saponin, dan steroid terhadap simplisia serbuk dan ekstrak etanol Akar Kelakai. Ekstraksi Akar Kelakai dilakukan dengan cara sokhletasi, lalu dilakukan identifikasi senyawa kimia spesifik secara KLT.

Pada penelitian ini diketahui bahwaAkarKelakaimengandungsenyawaaktif yang berpotensisebagaiafrodisiakayaitu alkaloid. Sedangkan profil KLT yang didapat adalah terdapatnya penampakan noda pada eluen non polar (Kloroform:Etil Asetat) dengan perbandingan 7:3, 8:2, 9:4 dengan masing-masing nilai $\mathrm{Rf}$ adalah 0,70 cm (7:3), 0,94 cm (8:2) dan 0,94 cm (9:4).
\end{abstract}

Kata Kunci: Akar Kelakai, Afrodisiaka, Identifikasi kimia, KLT

\section{ABSTRACT}

The necessity of traditional medicine is efficacious as aphrodisiac increasing every year. Dayak community believes that Kelakai roots have efficacy as a aphrodisiac drug, but no studies were conducted relating to the efficacy of the Kelakai roots. Traditional medicinal products are efficacious as aphrodisiac have a hormone-like effect, usually contain active ingredients that have estrogenic properties among other things, progesterone, androgenic, adaptogenic, and lektogenik. Materials that are androgenic or adaptogenic nature helps maintain and restore stamina. This research was aimed to determine the content of the active compound on the Kelakai roots that efficacious as aphrodisiac and to determine the 
profile of Thin Layer Chromatography (TLC) of active compound contained in Kelakai roots. This study used the identification method of chemical compounds such as starches and aleurone, tannins, catechols, flavonoids, alkaloids, saponins, and steroids for simplicia powder and ethanol extract of Kelakai roots. The extraction of Kelakai roots done by soxhletation, and TLC used to identify a specific chemical compound. The result showed that Kelakai Roots contain active compounds potentially aphrodisiac namely alkaloids and saponin. While the TLC profile obtained is the presence of stains on the appearance of a non-polar eluent (Chloroform: Ethyl Acetate) with a ratio of 7:3, 8:2, 9: 4 with each $\mathrm{Rf}$ value

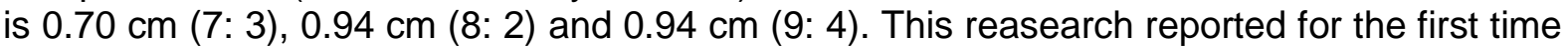
the potential of Kelakai roots as aphrodisiac. Thus, further work will focus on the study of pharmacological effects of Kelakai roots.

Key words:Kelakai Roots, Aphrodisiac, Identification Of Chemical Compounds, Thin Layer Chromatography

\section{PENDAHULUAN}

Pada saat ini masyarakat Indonesia secara umum semakin banyak menuju paradigma "Back to Nature" dengan memilih menggunakan bahan alami untuk mengatasi masalah kesehatan. WHO juga merekomendasikan penggunaan obat tradisional atau obat herbal dalam memelihara kesehatan masyarakat serta untuk pencegahan dan pengobatan penyakit terutama penyakit metabolic degenerative dan kanker (Katno, 2008).

Penggunaan bahan alam sebagai obat tradisional di Indonesia telah dilakukan oleh nenek moyang kita sejak berabad-abad yang lalu. Terbukti dari adanya naskah lama pada daun lontar husodo (Jawa), usada (Bali), lontarak pabbura (Sulawesi Selatan), dokumen serat primbon jampi, serat racikan boreh wulang dalem dan relief Candi Borobudur yang menggambarkan orang sedang meracik obat (jamu) dengan tumbuhan sebagai bahan bakunya (Sukandar, 2006).
Kalimantan merupakan pulau di Indonesia yang terkenal dengan kekayaan keanekaragaman hayatinya. Tak hanya itu, kekayaan pengetahuan pengobatan tradisional dengan menggunakan tumbuhan yang diwariskan secara lisan dari generasi ke generasi pada etnis asli Kalimantan juga sangat banyak (Noorcahyati, 2012).

Dalam hal perawatan kesehatan, umumnya masyarakat tradisional di Kalimantan saat ini sudah memanfaatkan fasilitas puskesmas yang ada. Namun, jika perawatan tidak kunjung sembuh atau beberapa penyakit ringan seperti demam, batuk dan sakit kepala, mereka menggunakan ramuan tumbuhan melalui pengobatan tradisional yang dikuasai oleh kaum tua atau tokoh adat setempat. Pengetahuan pengobatan tradisional ini sulit untuk didokumentasikan dan kurang begitu dihargai (FWI dan GFW, 2001).

Salah satu tumbuhan khas Kalimantan yang berkhasiat sebagai obat tradisional adalah kelakai. Kelakai 
merupakan tumbuhan yang lazim dikonsumsi oleh masyarakat seharisehari. Kelakai termasuk tumbuhan yang sangat mudah ditemukan didaerah Kalimantan. Tumbuhan ini banyak sekali terdapat dilingkungan tempat tinggal masyarakat Dayak. Masyarakat dapat dengan mudah memperolehnya tanpa harus membelinya di tempat tertentu. Selain sebagai bahan makanan, masyarakat Dayak percaya bahwa tumbuhan ini memiliki khasiat sebagai obat tradisional. Masyarakat Dayak percaya bahwa dengan mengkonsumsi daun kelakai dapat mengobati penyakit seperti anemia dan untuk ibu yang menyusui daun kelakai dipercaya dapat memperbanyak dan memperlancar produksi ASI.

Selama ini bagian kelakai yang dikonsumsi oleh masyakarat dan dipercayai sebagai bahan obat tradisional adalah bagian daun. Banyak penelitian yang sudah dilakukan untuk membuktikan kebenaran khasiat yang dimiliki oleh daun kelakai. Beberapa penelitian membuktikan bahwa daun kelakai mengandung zat aktif yaituzat besi ( $\mathrm{Fe})$, kalsium, vitamin $\mathrm{C}$, dan vitamin $\mathrm{A}$.

Ada satu bagiandari kelakai yangbelumbanyakdiketahuiolehmasyaraka tmemiliki khasiat sebagai obat tradisional. Bagian tumbuhan tersebut adalah akar. Akar Kelakai selama ini tidak dijadikan sebagaibahan makanan atau tidak dikonsumsi oleh masyarakat. Tetapi masyarakat Dayak asli percaya bahwa akar Kelakai memiliki khasiat sebagai obat afrodisiaka.

Penggunaan Akar Kelakai sebagai afrodisiaka berkaitan dengan masalah yang timbul sehubungan dengan gangguan seksual. Gangguan seksual tersebut meliputi penurunan libido seksual dan masalah disfungsi ereksi. Disfungsi ereksi merupakan masalah kesehatan yang penting karena berdampak terhadap kualitas hidup manusia (quality of life). Disfungsi ereksi dinyatakan sebagai ketidakmampuan seseorang mencapai atau mempertahankan ereksi penis yang cukup untuk melakukan hubungan seksual dengan sempurna. Data epidemiologi menunjukkan bahwa pada tahun 1995, jumlah penduduk dunia yang mengalami disfungsi ereksi sekitar 152 juta, dan pada tahun 2025 diperkirakan mencapai 322 juta (Sinrang et al., 2005).

Kebutuhan akan obat tradisional yang berkhasiat sebagai afrodisiaka semakin meningkat setiap tahunnya. Jika dilihat dari produk sediaan farmasi yang berasal dari zat kimia sintetis yang berkhasiat sebagai afrodisiaka masih sedikit ditemukan. Oleh karena itu pengembangan obat tradisional yang berkhasiat sebagai obat afrodisiaka sangat diperlukan. Sebagai tumbuhan asli Kalimantan Tengah, kelakai sebenarnya mempunyai nilai ekonomi yang sangat tinggi. Selama ini kelakai hanya dijadikan sebagai bahan makanan saja namun 
belum diproduksi menjadi suatu sediaan farmasi yang pastinya memiliki nilai jual yang tinggi. Penelitian ini bertujuan untuk mengetahui kandungan senyawa aktif yang berkhasiat sebagai afrodisiakapadaakar kelakaidan untuk mengetahui profil Kromatografi Lapis Tipis (KLT) senyawa aktif yang terkandung dalam akar kelakai.

\section{METODE PENELITIAN}

Penelitian ini dilakukan di Laboratorium Farmakognosi dan Farmakologi Fakultas IImu Kesehatan Universitas Muhammadiyah

Palangkaraya. Penelitian dilaksanakan selama 1 (satu) tahun dimulai dari sejak penelitian ini disetujui oleh Direktorat Jenderal Pendidikan Tinggi. Kegiatan penelitian yang dilakukan adalah pembuatan simplisia akar kelakai, ekstraksi akar kelakai, identifikasi senyawa kimia secara kualitatifi dan identifikasi senyawa kimia spesifik secara KLT.

\section{PembuatanSimplisia}

Simplisia Akar Kelakai dibuat dari Akar Kelakai segar yang diambil dari lahan gambut yang ada di kota palangkaraya.

PembuatansimplisiaakarKelakaimeliputi proses sortasibasah, pencucian, pengubahanbentuk, pengeringan, sortasikering, dan penyimpanan.

\section{Ektraksi akar Kelakai}

Akar Kelakai diekstraksi dengan metode ekstraksi panas yaitu sokhletasi. Menimbang serbuk Akar Kelakai sebanyak $500 \mathrm{mg}$, lalu dimasukkan ke dalam alat sokhletasi. Kemudian menambahkan pelarut Pelarut etanol hingga serbuk terendam, kemudian alat sokhletasi dirangkai dan sampel dibiarkan terekstrak selama 24 jam atau hingga warna sampel yang terendam pada pelarut telah berubah menjadi bening. Ekstrak cair yang didapat diambil lalu diuapkan hingga diperoleh ekstrak kental sampel Akar Kelakai.

\section{Identifikasi Senyawa Kimia}

Identifikasi senyawa kimia yang dilakukan menggunakan standar pemeriksaan kualitas simplisia yang tertuang di Materia Medika Indonesia. Senyawa-senyawa kimia yang diidentifikasi adalah pati, aleuron, katekol, alkaloid, saponin, flavonoid, tannin, dan steroid. Pemerikasaan senyawa kimia dilakukan dengan menambahkan pereaksi atau reagen yang sesuai. Analisi uji yang dilakukan adalah dengan melihat ada tidaknya perubahan warna setelah ditambahkan reagen yang sesuai dengan yang tertulis di literature.

\section{Identifikasi Senyawa Kimia Spesifik secara KLT}

Identifikasi senyawa kimia spesifik menggunakan ekstrak etanaol akar kelakai dengan menggunakan metode 
Fahruni, Rezqi Handayani dan Susi Novariyatiin

Kromatografi Lapis Tipis.Pada KLT dalam penelitian ini menggunakan dua macam eluen yaitu non polar dan eluen polar. Eluen non polar yang digunakan adalah nheksan : etil asetat dengan perbandingan 8:2, 7:3, 6:4 dan Kloroform : Etil Acetat dengan perbandingan 5:5, 6:4, 7:3, 8:2, 9:1. Serta eluen polar yang digunakan adalah etil asetat : etanol : air dengan perbandingan 10:2:1, 8:2:1, 6:2:1 dan $\mathrm{N}$ Butanol:Etil Asetat dengan perbandingan $8: 2,7: 3,6: 4$.
HASIL DAN PEMBAHASAN

Identifikasi Senyawa Kimia

Identifikasi senyawa kimia dilakukan dengan menggunakan simplisia serbuk Akar Kelakai dan ekstrak etanol akar Kelakai. Berdasarkan hasil identifikasi kimia pada simplisia serbuk Akar Kelakai dan ekstrak etanol akar kelakai menunjukkan hasil positif mengandung-mengandung senyawa kimia katekol, alkaloid, saponin dan tanin.

Tabel 1. Identifikasi Kimia Simplisia Akar Kelakai

\begin{tabular}{|c|c|c|c|c|}
\hline Komponen & Pereaksi & Acuan Pustaka* & Pengamatan & Hasil \\
\hline Pati & $\mathrm{I}_{2} 0,1 \mathrm{~N}$ & Sel berwarna biru & Sel berwarna cokelat & $(-)$ \\
\hline Aleuron & $\mathrm{I}_{2} 0,1 \mathrm{~N}$ & $\begin{array}{l}\text { Sel berwarna kuning } \\
\text { kecoklatan }\end{array}$ & Sel berwarna cokelat & $(-)$ \\
\hline Katekol & Vanili $10 \%$ & $\begin{array}{l}\text { Sel berwarna merah } \\
\text { intensif }\end{array}$ & $\begin{array}{l}\text { Sel berwarna merah } \\
\text { intensif }\end{array}$ & $(+)$ \\
\hline \multirow[t]{2}{*}{ Alkaloid } & Meyer & $\begin{array}{l}\text { Terbentuk endapan } \\
\text { kekuningan }\end{array}$ & $\begin{array}{l}\text { Terbentuk endapan } \\
\text { kekuningan }\end{array}$ & \multirow[b]{2}{*}{$(+)$} \\
\hline & Dragendorff & $\begin{array}{l}\text { Terbentuk endapan } \\
\text { jingga }\end{array}$ & Terbentuk endapan jingga & \\
\hline Saponin & $\mathrm{H}_{2} \mathrm{O}$ & $\begin{array}{l}\text { Terdapat busa yang } \\
\text { bertahan } \pm 10 \text { menit }\end{array}$ & $\begin{array}{l}\text { Terdapat busa yang } \\
\text { bertahan } \pm 10 \text { menit }\end{array}$ & $(+)$ \\
\hline Flavonoid & Uap $\mathrm{NH}_{3}$ & $\begin{array}{l}\text { Terbentuk warna } \\
\text { kuning intensif }\end{array}$ & $\begin{array}{l}\text { Tidak terbentuk warna } \\
\text { kuning intensif }\end{array}$ & $(-)$ \\
\hline \multirow[t]{3}{*}{ Tanin } & $\mathrm{HCl} 0,5 \mathrm{~N}$ & Terbentuk endapan & Tidak terbentuk endapan & \multirow{3}{*}{$(+)$} \\
\hline & $\mathrm{FeCl}_{3} 1 \mathrm{~N}$ & $\begin{array}{l}\text { Terbentuk warna biru } \\
\text { hitam }\end{array}$ & $\begin{array}{l}\text { Terbentuk warna biru } \\
\text { hitam }\end{array}$ & \\
\hline & $\mathrm{H}_{2} \mathrm{SO}_{4}$ & $\begin{array}{l}\text { Terbentuk endapan } \\
\text { cokelat kekuningan }\end{array}$ & $\begin{array}{l}\text { Terbentuk endapan } \\
\text { cokelat kekuningan }\end{array}$ & \\
\hline Steroid & $\begin{array}{l}\text { Lieberman } \\
\text { Burchard }\end{array}$ & $\begin{array}{l}\text { Terbentuk warna hijau } \\
\text { tua }\end{array}$ & $\begin{array}{l}\text { Tidak terbentuk warna } \\
\text { hijau tua }\end{array}$ & $(-)$ \\
\hline
\end{tabular}

Keterangan. (+) : Mengandung senyawa yang dimaksud

$(-)$ : Tidak mengandung senyawa yang dimaksud 
$\left(^{*}\right)$ : Materia Medika Indonesia Jilid VI Tahun 1995

Tabel 2. Identifikasi SenyawaKimia EkstrakEtanol Akar Kelakai

\begin{tabular}{|c|c|c|c|c|}
\hline Komponen & Pereaksi & Acuan Pustaka* & Pengamatan & Hasil \\
\hline Pati & $\mathrm{I}_{2} 0,1 \mathrm{~N}$ & Sel berwarna biru & Sel berwarna cokelat & $(-)$ \\
\hline Aleuron & $\mathrm{I}_{2} 0,1 \mathrm{~N}$ & $\begin{array}{l}\text { Sel berwarna kuning } \\
\text { kecoklatan }\end{array}$ & Sel berwarna cokelat & $(-)$ \\
\hline Katekol & Vanili $10 \%$ & $\begin{array}{l}\text { Sel berwarna merah } \\
\text { intensif }\end{array}$ & $\begin{array}{l}\text { Sel berwarna merah } \\
\text { intensif }\end{array}$ & $(+)$ \\
\hline \multirow[t]{2}{*}{ Alkaloid } & Meyer & $\begin{array}{l}\text { Terbentuk endapan } \\
\text { kekuningan }\end{array}$ & $\begin{array}{l}\text { Terbentuk endapan } \\
\text { kekuningan }\end{array}$ & \multirow[b]{2}{*}{$(+)$} \\
\hline & Dragendorff & $\begin{array}{l}\text { Terbentuk endapan } \\
\text { jingga }\end{array}$ & Terbentuk endapan jingga & \\
\hline Saponin & $\mathrm{H}_{2} \mathrm{O}$ & $\begin{array}{l}\text { Terdapat busa yang } \\
\text { bertahan } \pm 10 \text { menit }\end{array}$ & $\begin{array}{l}\text { Terdapat busa yang } \\
\text { bertahan } \pm 10 \text { menit }\end{array}$ & $(+)$ \\
\hline Flavonoid & Uap $\mathrm{NH}_{3}$ & $\begin{array}{l}\text { Terbentuk warna } \\
\text { kuning intensif }\end{array}$ & $\begin{array}{l}\text { Tidak terbentuk warna } \\
\text { kuning intensif }\end{array}$ & $(-)$ \\
\hline \multirow[t]{3}{*}{ Tanin } & $\mathrm{HCl} 0,5 \mathrm{~N}$ & Terbentuk endapan & Tidak terbentuk endapan & \multirow{3}{*}{$(+)$} \\
\hline & $\mathrm{FeCl}_{3} 1 \mathrm{~N}$ & $\begin{array}{l}\text { Terbentuk warna biru } \\
\text { hitam }\end{array}$ & $\begin{array}{l}\text { Terbentuk warna biru } \\
\text { hitam }\end{array}$ & \\
\hline & $\mathrm{H}_{2} \mathrm{SO}_{4}$ & $\begin{array}{l}\text { Terbentuk endapan } \\
\text { cokelat kekuningan }\end{array}$ & $\begin{array}{l}\text { Terbentuk endapan } \\
\text { cokelat kekuningan }\end{array}$ & \\
\hline Steroid & $\begin{array}{l}\text { Lieberman } \\
\text { Burchard }\end{array}$ & $\begin{array}{l}\text { Terbentuk warna hijau } \\
\text { tua }\end{array}$ & $\begin{array}{l}\text { Tidak terbentuk warna } \\
\text { hijau tua }\end{array}$ & $(-)$ \\
\hline
\end{tabular}

Keterangan. (+) : Mengandung senyawa yang dimaksud

$(-)$ : Tidak mengandung senyawa yang dimaksud

$\left(^{*}\right)$ : Materia Medika Indonesia Jilid VI Tahun 1995

Jika dilihat dari kedua hasil tersebut dugaan awal dengan menggunakan metode kualitatif menunjukkan Akar Kelakai positif mengandung senyawa kimia yaitu katekol, alkaloid, saponin dan tanin. Berdasarkan hasil ini sudah dapat membuktikan secara ilmiah data empiris dari masyarakat bahwa Akar Kelakai dapat berkhasiat sebagai obat. Karena kandungan senyawa kimia yang terdapat di Akar Kelakai menunjukkan adanya efek farmakologis walaupun untuk hal tersebut haruslah dilakukan penelitian kearah efikasi dengan menggunakan hasil penelitian ini sebagai acuan. Jika dilihat data empiris yang didapat bahwa Akar Kelakai diduga mempunyai khasiat sebagai afrodisiaka maka hasil identifikasi kimia menunjukkan hal yang sesuai. Hal ini dikarenakan diantara senyawa metabolit sekunder yang berperan dalam aktivitas afrodisiaka adalah saponin dan 
Fahruni, Rezqi Handayani dan Susi Novariyatiin

alkaloid. Alkaloid sendiri merupakan

terbesar baik jumlah maupun

penyebarannya. Alkaloid banyak

dimanfaatkan di bidang farmasi karena memiliki efek fisiologis yang berdampak positif dalam tubuh. Beberapa efek farmakologis yang dihasilkan oleh alkaloid adalah antiinflamasi, anti kanker, antitoksin, obat luka bakar, afrodisiaka, obat jantung dan lain-lain. alkaloid tidak hanya memiliki aksi sentral namun juga memiliki aksi perifer, yaitu dengan membantu relaksasi otot polos corpus cavernosum yang memicu terjadinya ereksi. Mekanisme sentral yang dimiliki oleh alkaloid adalah meningkatkan pelepasan nitric oxide dari endothelial dan ujung saraf. Alkaloid diketahui memiliki peranan dalam menginduksi vasodilatasi sehingga menimbulkan ereksi. Alkaloid meningkatkan dilatasi pembuluh darah pada alat kelamin pria (Silva et al, 2012).

Saponin meningkatkan libido melalui mekanisme kerja langsung pada sistem saraf pusat dan jaringan gonad. Aksi sentral dari saponin yaitu meningkatkan kadar LH dan FSH, meningkatkan produksi androgen melalui jalur langsung maupun tidak langsung. Saponin (steroid glikosida) berperan dalam biosintesis DHEA (dehydroepiandrosteron) sehingga meningkatkan kadar testosteron dalam tubuh dan memacu libido.Melalui mekanisme ini, saponin mampu meningkatkan kadar hormon testosteron.Kadar testosteron dilaporkan senyawa organik bahan alam yang memiliki hubungan dengan $\mathrm{LH}$ dan $\mathrm{FSH}$, seperti peningkatan kadar gonadotropin bersamaan dengan peningkatan kadar testosteron (Pratabdanrajendar, 2012).

Melalui berbagai mekanisme inilah, senyawa aktif dalam akarkelakaidapat menimbulkan peningkatan libido sehingga mampu mendorong perilaku seksual dan disebut dengan efek afrodisiaka.

\section{Identifikasi Senyawa Kimia Spesifik secara KLT}

Tujuan dari metode KLT pada penelitian ini adalah untuk menentukan eluen yang sesuai untuk senyawa kimia yang terkandung di dalam ekstrak etanol Akar Kelakai dan untuk melihat profil noda dari senyawa kimia yang terkandung di dalamnya. Pada penelitian KLT menggunakan fase diam lempeng silica gel dan fase geraknya berupa eluen polar (Etil Asetat : Etanol : Air) dengan perbandingan 10:2:1, 8:2:1, 6:2:1, dan non polar (N-Heksan : Etil Asetat) dengan perbandingan 8:2, 7:3, 6:4.

Hasil yang didapat untuk eluen non polar yaitu tidak adanya penampakan noda atau senyawa kimia yang terdapat pada ekstrak etanol, tidak mengalami pemisahan baik sebelum dilihat di UV maupun setelah dilihat di UV. Begitu juga ketika disemprot dengan menggunakan indikator asam yaitu $\mathrm{H}_{2} \mathrm{SO}_{4}$ tidak terlihat adanya noda. Sedangkan pada eluen polar terjadi penampakan noda tetapi 
noda yang berekor artinya tidak terpisah dengan sempurna. Terjadinya noda berekor kemungkinan disebabkan eluen yang digunakan tidak sesuai dengan senyawa kimia yang terkandung. Untuk memastikan hal tersebut tim peneliti melakukan pengulangan sebanyak 3 kali dengan menggunakan eluen yang sama. Dan hasil yang didapat semunya menunjukkan hal yang sama tidak menemukan penampakan noda yang baik. Oleh karena itu tim peneliti memutuskan untuk melakukan KLT kembali tetapi dengan menggunakan eluen yang berbeda. Berdasarkan hasil yang didapat dari penampakan noda di eluen polar (Etil Asetat : Etanol : Air), tim peneliti memutuskan untuk mengurangi kepolaran dari eluen. Dan eluen yang digunakan adalah eluen non polar (Kloroform:Etil asetat) dengan perbandingan $5: 5,: 4,7: 3$, 8:2, 9:1 dan eluen polar (N-Butanol:Etil Asetat) dengan perbandingan 8:2, 7:3, 6:4. Hasil yang didapat menunjukkan pada saat dilakukan pemisahan dengan menggunakan eluen non polar tidak menampakkan adanya noda baik sebelum dilihat dengan menggunakan sinar UV maupun setelah dilihat di UV. Tetapi setelah dilakukan penyemprotan dengan menggunakan $\mathrm{H}_{2} \mathrm{SO}_{4}$ terdapat noda untuk perbandingan $7: 3, \quad 8: 2$, dan 9:1. Penampakan noda yang muncul termasuk kriteria noda yang baik karena nilai Rfnya dapat dihitung dan memberikan warna yaitu warna ungu. Nilai $\mathrm{Rf}$ yg didapat adalah $0,70 \mathrm{~cm}$ (7:3), 0,94 cm (8:2) dan $0,94 \mathrm{~cm}(9: 4)$. Sedangkan untuk eluen polar (N-Butanol:Etil Asetat) tidak menunjukkan adanya penampakan noda.

Tabel 3. Hasil Uji KLT Ekstrak Etanol Akar Kelakai Dengan Pengamatan Menggunakan Pereaksi Semprot $\mathrm{H}_{2} \mathrm{SO}_{4}$ (N-Butanol : Etil asetat)

\begin{tabular}{|c|c|c|c|c|}
\hline No & $\begin{array}{c}\text { PerbandinganEluen } \\
\text { (N-Butanol : Etil asetat) }\end{array}$ & $\begin{array}{c}\text { Jarak } \\
\text { Bercak } \\
\text { Noda }\end{array}$ & $\begin{array}{c}\text { JarakPelar } \\
\text { ut }\end{array}$ & $\begin{array}{c}\text { NilaiRf } \\
\text { Ekstraketanol }\end{array}$ \\
\hline 1 & $8: 2$ & - & $8,5 \mathrm{~cm}$ & - \\
\hline 2 & $7: 3$ & - & $8,5 \mathrm{~cm}$ & - \\
\hline 3 & $6: 4$ & - & $8,5 \mathrm{~cm}$ & - \\
\hline
\end{tabular}

Keterangan. (-) : Tidak terjadi pemisahan.

Tabel 4. Hasil Uji KLT Ekstrak Etanol Akar Kelakai Dengan Pengamatan Menggunakan Pereaksi Semprot $\mathrm{H}_{2} \mathrm{SO}_{4}$ (Kloroform : Etil asetat)

\begin{tabular}{|c|c|c|c|c|}
\hline No & $\begin{array}{c}\text { PerbandinganEluen } \\
\text { (Kloroform : Etil asetat) }\end{array}$ & $\begin{array}{c}\text { Jarak } \\
\text { Bercak } \\
\text { Noda }\end{array}$ & $\begin{array}{c}\text { JarakPelar } \\
\text { ut }\end{array}$ & $\begin{array}{c}\text { NilaiRf } \\
\text { Ekstraketanol }\end{array}$ \\
\hline 1 & $9: 1$ & $8 \mathrm{~cm}$ & $8,5 \mathrm{~cm}$ & 0,94 \\
\hline
\end{tabular}


Fahruni, Rezqi Handayani dan Susi Novariyatiin

\begin{tabular}{|c|c|c|c|c|}
\hline 2 & $8: 2$ & $8 \mathrm{~cm}$ & $8,5 \mathrm{~cm}$ & 0,94 \\
\hline 3 & $7: 3(\mathrm{a})$ & $7,5 \mathrm{~cm}$ & $8,5 \mathrm{~cm}$ & 0,88 \\
\hline 4 & $7: 3(\mathrm{~b})$ & $6 \mathrm{~cm}$ & $8,5 \mathrm{~cm}$ & 0,70 \\
\hline 5 & $6: 4$ & - & $8,5 \mathrm{~cm}$ & - \\
\hline 6 & $5: 5$ & - & $8,5 \mathrm{~cm}$ & - \\
\hline
\end{tabular}

Keterangan. (-) : Tidak terjadi pemisahan.

Berdasarkan hasil KLT yang telah diperoleh dapat disimpulkan bahwa eluen yang memilki sifat yang sesuai dengan senyawa kimia yang terkandung di dalam ekstrak etanol Akar Kelakai adalah eluen nonpolar (Kloroform:Etil Asetat) dengan perbandingan 7:3, 8:2, 9:1. Dari hasil tersebut juga diketahui bahwa senyawa kimia yang terkandung di dalam ekstrak etanol Akar Kelakai memilki kecenderungan bersifat non polar. Dan dari KLT yang telah dilakukan didapatkan profil noda yang baik karena telihat pada hasilnya noda yang terlihat terpisah dengan baik sehingga nilai Rfnya bisa dihitung.

\section{KESIMPULAN}

Kesimpulan yang didapat dari penelitian ini adalah:

1. Hasil analisis kualitatif menunjukkan Akar Kelakai mengandung senyawa aktif yang berpotensi sebagai afrodisiaka yaitu alkaloid an saponin.

2. Profil KLT yang didapat adalah terdapatnya penampakan noda pada eluen non polar (Kloroform : Etil Asetat) dengan perbandingan 7:3, 8:2, 9:4 dengan masing-masing nilai
Rf adalah 0,70 cm (7:3), 0,94 cm (8:2) dan 0,94 cm (9:4).

\section{DAFTAR PUSTAKA}

DepKes, R.I. Materia Medika Indonesia. Jakarta.

FWI dan GFW. 2001. Potret Keberadaan Hutan Indonesia. Bogor, Indonesia. Forest Watch Indonesia dan Washington D.C. Global Forest Watch.

Katno, 2008. Tingkat Manfaat, Keamanan, Dan Efektifitas Tanaman Obat Dan Obat Tradisional. Tawamangu: Badan Penelitian Dan Pengembangan Kesehatan Departemen Kesehatan RI. Hal. 3; 15; 41 dalam Dewi, A.A.A.P.K., Warditiani, N.K., Leliqia, N.P.E. Inventarisasi Obat Dalam Usaha Upas Dalam Bentuk Buku Elektronik. Bali: Fakultas MIPA, Universitas Udayana

Noorcahyati. 2012. Tumbuha nBerkhasiat Obat Etnis Asli Kalimantan. Balik papan :Balai Penelitian Teknologi Konservasi Sumber Daya Alam.

Pratap SA, and Rajender S. 2012. Potent Natural Aphrodisiacs For The Management Of Erectile 
Dysfunction And Male Sexual

Disabilities. Frontiers in

Bioscience. Pubmed. 1(4):167-80.

Silva CV, Borges FM, Velozo ES. 2012.

Phytochemistry Of Some Brazilian

Plants With Aphrodisiac Activity.

Phytochemicals - A Global

Perpective of Their Role in

Nutrition and HealthAvailable from:

Intechopen

Sinrang, A. Wardihan, I. Idris, I. Patelongi,

Y. Tandiroongan\& M. Susanty.

2005. Disfungsi Ereksidan

Hipertensi. J Med Nus Vol. 26 No.

1 Januari-Maret 2005.

Sukandar E Y. 2006. Tren Dan Paradigma

Dunia Farmasi, Industri Klinik

Teknologi Kesehatan. Bandung :

ITB. Dalam Kumalasari, L O R. 2006. Pemanfaatan Obat

Tradisional Dengan Pertimbangan

Manfaat Dan Keamanan. Jember

:Artikel Majalah IImu Kefarmasian

Vol. 3 No. 1 Hal. 1-7 Universitas

Jember. 